\title{
Improving synchrony in young infant supported by noninvasive ventilation for severe bronchiolitis: Yes we can... so we should!
}

\author{
Milesi Christophe $^{1}$, Julien Baleine ${ }^{1}$, and GILLES CAMBONIE ${ }^{1}$ \\ ${ }^{1}$ University Hospital Centre Montpellier
}

September 11, 2020

\section{Improving synchrony in young infant supported by noninvasive ventilation for severe bronchi- olitis: Yes we can... so we should!}

C Milési, $\mathrm{MD}^{1}$, J Baleine, $\mathrm{MD}^{1}$, G Cambonie, $\mathrm{MD}, \mathrm{PhD}^{1}$

${ }^{1}$ Department of Neonatal Medicine and Pediatric Intensive Care, Arnaud de Villeneuve Hospital, Montpellier University Hospital Center, Montpellier, France

Correspondence: Christophe Milési, MD, Department of Neonatal Medicine and Pediatric Intensive Care Unit, Arnaud de Villeneuve Hospital, Montpellier University Hospital, 371 Avenue du Doyen Gaston Giraud, 34295 Montpellier Cedex 5, France

Tel: +33467336 556, Fax: +33467336 228, e-mail:c-milesi@chu-montpellier.fr

Word count: 1391; references: 43

Keywords: asynchrony, bronchiolitis, noninvasive ventilation, neurally adjusted ventilatory assist, infant

Admission to a pediatric intensive care unit (PICU) is required for 9-14\% of infants with acute viral bronchiolitis (AVB) and evolving respiratory distress. ${ }^{1,2}$ In this context, AVB generally presents as severe obstructive lung disease, which causes an increased load on the respiratory muscles. ${ }^{3,4}$ As no pharmaceutical treatment currently in use is able to rapidly reduce airway obstruction, the management of these patients is focused on providing respiratory support to reduce respiratory muscle fatigue and prevent intubation. Noninvasive ventilation (NIV), delivered by continuous positive airway pressure (CPAP) or bilevel positive airway pressure (BiPAP), has traditionally been applied and is associated with reductions in intubation rates, ventilationassociated complications, and duration and cost of hospitalization. ${ }^{5,6}$ More recently, a third device was introduced to administer a heated and humidified mixture of air and oxygen with high-flow nasal cannulae (HFNC). PICU clinicians thus currently have at their disposal several respiratory assistance modalities for infants with moderate to severe AVB, but few high-grade evidence studies to guide their choice. ${ }^{7}$ Indeed, most of the studies carried out in this field have been observational, with comparisons with historical cohorts, ${ }^{5,6,8-10}$ or physiological, assessing differences with and without noninvasive respiratory support. ${ }^{4,11-13}$

In this issue of Pediatric Pulmonology, Delacroix et al. re-evaluates the use of BiPAP as the first-line respiratory support in less-than-6-months patients with bronchiolitis. ${ }^{14}$ In their single-center retrospective study, they report longer durations of noninvasive support and longer PICU stays in the patients supported with BiPAP compared with CPAP and HFNC. The authors should be congratulated for this analysis covering more than 250 infants, one of the largest cohorts treated with this device. This work usefully complements the information provided by two recent observational studies that focused on the comparison of these three techniques in this specific group of patients. ${ }^{15,16}$ The inherent limitation of these retrospective studies, whether monocentric ${ }^{14,16}$ or database-driven, ${ }^{15}$ is the presence of confounders, which influence both the choice of the initial respiratory support and the outcome. It was particularly interesting to note in Delacroix 
et al.'s study that the clinicians' preferred choice was BiPAP, although no local written protocol required it in this situation. However, the BiPAP-treated group also included a higher rate of premature infants, a condition associated with the immaturity of immune defenses and airway development and ventilation-induced airway injury that predisposes to more severe bronchiolitis. ${ }^{17}$

Several national and multinational surveys have demonstrated that pediatric intensivists currently select HFNC for initial respiratory care in cases of severe bronchiolitis. ${ }^{18,19}$ This popularity among caregivers appears to be associated with the perception of a technique that is easy to implement, with comparable effectiveness and fewer complications than CPAP. ${ }^{20}$ The physiological background for using CPAP in this instance is that the application of nearly constant pressure support is associated with rapid unloading of respiratory muscles, increased expiratory time, and concomitantly improved respiratory distress. ${ }^{4,11,21}$ Reduced respiratory effort and a change in breathing pattern suggest that CPAP improves the work of breathing by offsetting the patient's inspiratory effort to overcome intrinsic end-expiratory pressure (PEEPi). In addition, positive airway pressure helps maintain airway patency and alleviate bronchiolar obstruction, a 'stenting' effect that in turn reduces respiratory system resistance. HFNC also generates some degree of airway distenting pressure, which supports inspiratory effort. The reduced diaphragmatic electrical activity and decreased esophageal pressure swings also confirm the effectiveness of HFNC to reduce the work of breathing in AVB. ${ }^{12,13}$

Randomized controlled trials, however, have found that neither CPAP nor HFNC reduces the need for intubation in infants with bronchiolitis, probably due to the current low occurrence of this event ${ }^{1,2,21-24}$ In practice, CPAP and HFNC are introduced early in the course of the disease - even as a preemptive measure in some cases - in infants generally not exhausted. While NIV is widely used to treat bronchiolitis, ${ }^{25}$ most clinicians, unlike in Delacroix et al.'s study, ${ }^{14}$ consider BiPAP the next step for patients failing with HFNC or CPAP. ${ }^{19}$ Failure rates vary widely, from $10 \%$ to $50 \%$ in the major randomized controlled studies, ${ }^{1,2,22-24}$ and depend on multiple factors, the most important probably related to the criteria and delays in defining failure. According to the TRAMONTANE study, the main causes of failure are worsening respiratory distress, especially in patients supported by HFNC; patient discomfort, the leading cause in patients treated with CPAP; and the occurrence of apnea in a minority of cases in both groups. ${ }^{22}$ The very large cohort of almost 6500 patients collected by Clayton et al. ${ }^{15}$ in more than 90 PICUs in North America and Saudi Arabia gives credit to clinicians who turn to NIV in the event of failure, since this strategy seems to avoid escalation to invasive mechanical ventilation (IMV) in more than $70 \%$ of cases. There is a rationale for using BiPAP in infants with bronchiolitis and worsening respiratory failure, but is this technique being used optimally?

Delacroix et al. point out that the unfavorable results in their BiPAP group may have resulted from a suboptimal patient-ventilator interaction. ${ }^{14}$ Indeed, use of pressure support in spontaneous/timed modes requires inspiratory synchrony, expiratory synchrony, and rapid compensation for leaks in order to reach preestablished pressure values during inspiration. ${ }^{26}$ Infants, especially when exhausted, have a higher respiratory rate, lower tidal volume, and weaker inspiratory efforts, making synchronization with their ventilator more complex. ${ }^{27}$ Patient-ventilator asynchrony is frequent during IMV or NIV with pressure support in infants and children. ${ }^{28,29}$ In an elegant physiological study performed in infants with AVB, Baudin et al. characterized the main inspiratory asynchronies with noninvasive pressure assist control ventilation from diaphragmatic electrical activity recordings. ${ }^{30}$ Autotriggering, double triggering, and above all non-triggered breaths were observed for nearly $40 \%$ of the respiratory cycles, highlighting difficulties in detecting inspiratory effort in patients younger than 6 months, the targeted population in the study by Delacroix et al. ${ }^{14}$ These triggering asynchronies are associated with leaks, notably when BiPAP is performed with a nasal interface. ${ }^{31}$ This issue is explained by the insufficient sensitivity of the triggers with regard to the modest volumes and flows generated during inspiration at this young age. ${ }^{32}$ In addition, airway obstruction and dynamic hyperinflation may increase the frequency of ineffective respiratory efforts. ${ }^{30}$ The asynchrony index could be even higher if premature and late cycling are considered, i.e., asynchronies related to excessively long or short ventilator inspiratory times in relation to the neural command. ${ }^{28}$ These expiratory asynchronies are influenced by the ventilator's mode and algorithm and may be improved by adjustments of the cycling-off criterion, which remains a difficult bedside challenge. ${ }^{28}$ 
In adults, patient-ventilator asynchrony has been associated with increased duration of mechanical ventilation, sleep disorders, prolonged ICU stay, and increased mortality. ${ }^{33}$ Such a demonstration has not been made in pediatrics, but recognition of this phenomenon and the analysis of its risk factors and consequences are much more recent. ${ }^{34}$ Currently, technological advances in ventilators have opened new horizons regarding synchronization, even in this group of patients. NIV software, management of leaks, and turbines specifically dedicated to NIV are indisputable advances. ${ }^{35}$ Neurally adjusted ventilatory assist (NAVA), initially developed for intubated patients, offers another option. In the field of severe AVB, an early report highlighted the interest of NAVA in providing less aggressive IMV and more comfort to the child. ${ }^{36}$ Discomfort during NIV is common in infants, ${ }^{22}$ and the prescription of sedatives is systematically considered by some teams. ${ }^{37}$ The discomfort may have multiple origins, including intolerance of the interface, skin breakdown, conjunctivitis, and gastric distension. ${ }^{38}$ Patient-ventilator asynchrony is another important source, ${ }^{39}$ which can be significantly improved with NAVA. Indeed, the direct analysis of diaphragmatic depolarization reduces the trigger delay, leading to more effective synchronization than with conventional NIV, even after careful optimization of the expiratory trigger setting. ${ }^{28,30,40}$ The asynchrony index may be reduced to $2 \%-8 \%$, i.e., lower than the critical threshold of $10 \%$ defined in the adult population, ${ }^{41}$ with a nasal interface and in the presence of large leaks. One of the restraints on using NAVA is the extra cost it entails. However, the targeted population is limited to HFNC or CPAP failure, corresponding to $10-15 \%$ of moderate to severe AVB. ${ }^{15}$ A recent physiological study in severe AVB infants found that, compared to CPAP, NAVA was associated with a decreased work of breathing, lower neural drive and lower Ti/Ttot ratio. ${ }^{42}$ The promising results of this study suggest that pediatric intensivists must be as ambitious in combating asynchrony as they have been in combating pain and discomfort. ${ }^{43}$ The impact on patient outcome will be judged in randomized controlled trials targeting severe forms of the disease.

Disclosure: The authors declare no conflict of interest.

\section{References}

1. Kepreotes E, Whitehead B, Attia J, Oldmeadow C, Collison A, Searles A, Goddard B, Hilton J, Lee M, Mattes J. High-flow warm humidified oxygen versus standard low-flow nasal cannula oxygen for moderate bronchiolitis (HFWHO RCT): an open, phase 4, randomised controlled trial. Lancet. 2017;389:930-939. doi: 10.1016/S0140-6736(17)30061-2.

2. Franklin D, Babl FE, Schlapbach LJ, Oakley E, Craig S, Neutze J, Furyk J, Fraser JF, Jones M, Whitty JA, et al. A randomized trial of high-flow oxygen therapy in infants with bronchiolitis. $N$ Engl J Med . 2018;378:1121-1131. doi: 10.1056/NEJMoa1714855.

3. Stokes GM, Milner AD, Groggins RC. Work of breathing, intra-thoracic pressure and clinical findings in a group of babies with bronchiolitis.Acta Paediatr Scand. 1981;70:689-94. doi: 10.1111/j.16512227.1981.tb05769.x.

4. Cambonie G, Milési C, Jaber S, Amsallem F, Barbotte E, Picaud JC, Matecki S. Nasal continuous positive airway pressure decreases respiratory muscles overload in young infants with severe acute viral bronchiolitis. Intensive Care Med. 2008;34:1865-72. doi: 10.1007/s00134-008-1201-x.

5. Javouhey E, Barats A, Richard N, Stamm D, Floret D. Non-invasive ventilation as primary ventilatory support for infants with severe bronchiolitis. Intensive Care Med . 2008;34:1608-14. doi: 10.1007/s00134-0081150-4.

6. Essouri S, Laurent M, Chevret L, Durand P, Ecochard E, Gajdos V, Devictor D, Tissières P. Improved clinical and economic outcomes in severe bronchiolitis with pre-emptive nCPAP ventilatory strategy.Intensive Care Med. 2014;40:84-91. doi: 10.1007/s00134-013-3129-z.

7. Franklin D, Fraser JF, Schibler A. Respiratory support for infants with bronchiolitis, a narrative review of the literature. Paediatr Respir Rev. 2019;30:16-24. doi: 10.1016/j.prrv.2018.10.001.

8. McKiernan C, Chua LC, Visintainer PF, Allen H. High flow nasal cannulae therapy in infants with 
bronchiolitis. J Pediatr.2010;156:634-8. doi: 10.1016/j.jpeds.2009.10.039.

9. Schibler A, Pham TM, Dunster KR, Foster K, Barlow A, Gibbons K, Hough JL. Reduced intubation rates for infants after introduction of high-flow nasal prong oxygen delivery. Intensive Care Med. 2011;37:847-52. doi: 10.1007/s00134-011-2177-5.

10. Ganu SS, Gautam A, Wilkins B, Egan J. Increase in use of non-invasive ventilation for infants with severe bronchiolitis is associated with decline in intubation rates over a decade.Intensive Care Med. 2012;38:1177-83. doi: 10.1007/s00134-012-2566-4.

11. Essouri S, Durand P, Chevret L, Balu L, Devictor D, Fauroux B, Tissières P. Optimal level of nasal continuous positive airway pressure in severe viral bronchiolitis. Intensive Care Med.2011;37:2002-7. doi: 10.1007/s00134-011-2372-4.

12. Milési C, Baleine J, Matecki S, Durand S, Combes C, Novais AR, Cambonie G. Is treatment with a high flow nasal cannula effective in acute viral bronchiolitis? A physiologic study. Intensive Care Med. 2013;39:1088-94. doi: 10.1007/s00134-013-2879-y.

13. Pham TM, O'Malley L, Mayfield S, Martin S, Schibler A. The effect of high flow nasal cannula therapy on the work of breathing in infants with bronchiolitis. Pediatr Pulmonol. 2015;50:713-20. doi: 10.1002/ppul.23060.

14. Delacroix E, Millet A, Pin I, Mortamet G. Use of bilevel positive pressure ventilation in patients with bronchiolitis. Pediatr Pulmonol . 2020;

15. Clayton JA, McKee B, Slain KN, Rotta AT, Shein SL. Outcomes of children with bronchiolitis treated with high-flow nasal cannula or noninvasive positive pressure ventilation. Pediatr Crit Care Med.2019;20:128135. doi: 10.1097/PCC.0000000000001798.

16. Habra B, Janahi IA, Dauleh H, Chandra P, Veten A. A comparison between high-flow nasal cannula and noninvasive ventilation in the management of infants and young children with acute bronchiolitis in the PICU. Pediatr Pulmonol. 2020;55:455-461. doi: 10.1002/ppul.24553.

17. Schuh S, Kwong JC, Holder L, Graves E, Macdonald EM, Finkelstein Y. Predictors of critical care and mortality in bronchiolitis after emergency department discharge. J Pediatr. 2018;199:217-222.e1. doi: 10.1016/j.jpeds.2018.04.010.

18. Bradshaw ML, Déragon A, Puligandla P, Emeriaud G, Canakis AM, Fontela PS. Treatment of severe bronchiolitis: A survey of Canadian pediatric intensivists. Pediatr Pulmonol. 2018;53:613-618. doi: 10.1002/ppul.23974.

19. Kawaguchi A, Garros D, Joffe A, DeCaen A, Thomas NJ, Schibler A, Pons-Odena M, Udani S, Takeuchi M, Junior JC, et al. Variation in practice related to the use of high flow nasal cannula in critically ill children. Pediatr Crit Care Med. 2020;21:e228-e235. doi: 10.1097/PCC.0000000000002258.

20. Hosheh O, Edwards CT, Ramnarayan P. A nationwide survey on the use of heated humidified high flow oxygen therapy on the paediatric wards in the UK: current practice and research priorities. $B M C$ Pediatr.2020;20:109. doi: 10.1186/s12887-020-1998-1.

21. Milési C, Matecki S, Jaber S, Mura T, Jacquot A, Pidoux O, Chautemps N, Novais AR, Combes C, Picaud JC, et al. $6 \mathrm{cmH} 2 \mathrm{O}$ continuous positive airway pressure versus conventional oxygen therapy in severe viral bronchiolitis: a randomized trial. Pediatr Pulmonol.2013;48:45-51. doi: 10.1002/ppul.22533.

22. Milési C, Essouri S, Pouyau R, Liet JM, Afanetti M, Portefaix A, Baleine J, Durand S, Combes C, Douillard A, et al. High flow nasal cannula (HFNC) versus nasal continuous positive airway pressure (nCPAP) for the initial respiratory management of acute viral bronchiolitis in young infants: a multicenter randomized controlled trial (TRAMONTANE study). Intensive Care Med. 2017;43:209-216. doi: 10.1007/s00134-016$4617-8$. 
23. Milési C, Pierre AF, Deho A, Pouyau R, Liet JM, Guillot C, Guilbert AS, Rambaud J, Millet A, Afanetti M, et al. A multicenter randomized controlled trial of a $3-\mathrm{L} / \mathrm{kg} / \mathrm{min}$ versus $2-\mathrm{L} / \mathrm{kg} / \mathrm{min}$ high-flow nasal cannula flow rate in young infants with severe viral bronchiolitis (TRAMONTANE 2). Intensive Care Med. 2018;44:1870-1878. doi: 10.1007/s00134-018-5343-1.

24. Yurtseven A, Turan C, Erseven E, Saz EU. Comparison of heated humidified high-flow nasal cannula flow rates $\left(1-\mathrm{L}^{*} \mathrm{~kg}^{*} \mathrm{~min}^{-1}\right.$ vs $\left.2-\mathrm{L}^{*} \mathrm{~kg}^{*} \mathrm{~min}^{-1}\right)$ in the management of acute bronchiolitis. Pediatr Pulmonol.2019;54:894-900. doi: 10.1002/ppul.24318.

25. Mayordomo-Colunga J, Pons-Odena M, Medina A, Rey C, Milesi C, Kallio M, Wolfler A, Garcia-Cusco M, Demirkol D, Garcia-Lopez M, et al. Non-invasive ventilation practices in children across Europe.Pediatr Pulmonol. 2018;53:1107-1114. doi: 10.1002/ppul.23988.

26. Modesto V, Vidal S, Ibiza E. Physiology of respiratory dynamics. Application to non-invasive ventilation. In: Medina A, Pons-Odena M, Martinon-Torres F, editors. Non invasive ventilation in pediatrics. Madrid/Barcelona: Ergon; 2015. p 11-14.

27. Beck J, Reilly M, Grasselli G, Mirabella L, Slutsky AS, Dunn MS, Sinderby C. Patient-ventilator interaction during neurally adjusted ventilatory assist in low birth weight infants. Pediatr Res.2009;65:6638. doi: 10.1203/PDR.0b013e31819e72ab.

28. Vignaux L, Grazioli S, Piquilloud L, Bochaton N, Karam O, Levy-Jamet Y, Jaecklin T, Tourneux P, Jolliet P, Rimensberger PC. Patient-ventilator asynchrony during noninvasive pressure support ventilation and neurally adjusted ventilatory assist in infants and children. Pediatr Crit Care Med. 2013;14:e357-64. doi: 10.1097/PCC.0b013e3182917922.

29. Mortamet G, Larouche A, Ducharme-Crevier L, Flechelles O, Constantin G, Essouri S, Pellerin-Leblanc AA, Beck J, Sinderby C, Jouvet P, et al. Patient-ventilator asynchrony during conventional mechanical ventilation in children. Ann Intensive Care. 2017;7:122. doi: 10.1186/s13613-017-0344-8.

30. Baudin F, Pouyau R, Cour-Andlauer F, Berthiller J, Robert D, Javouhey E. Neurally adjusted ventilator assist (NAVA) reduces asynchrony during non-invasive ventilation for severe bronchiolitis.Pediatr Pulmonol. 2015;50:1320-7. doi: 10.1002/ppul.23139.

31. Mortamet G, Amaddeo A, Essouri S, Renolleau S, Emeriaud G, Fauroux B. Interfaces for noninvasive ventilation in the acute setting in children. Paediatr Respir Rev. 2017;23:84-88. doi: 10.1016/j.prrv.2016.09.004.

32. Schmalisch G, Wilitzki S, Wauer RR. Differences in tidal breathing between infants with chronic lung diseases and healthy controls.BMC Pediatr. 2005;5:36. doi: 10.1186/1471-2431-5-36.

33. Murias G, Lucangelo U, Blanch L. Patient-ventilator asynchrony.Curr Opin Crit Care. 2016;22:53-9. doi: 10.1097/MCC.0000000000000270.

34. Blokpoel RG, Burgerhof JG, Markhorst DG, Kneyber MC. Patient-ventilator asynchrony during assisted ventilation in children.Pediatr Crit Care Med. 2016;17:e204-11. doi: 10.1097/PCC.000000000000669.

35. Carteaux G, Lyazidi A, Cordoba-Izquierdo A, Vignaux L, Jolliet P, Thille AW, Richard JM, Brochard L. Patient-ventilator asynchrony during noninvasive ventilation: a bench and clinical study. Chest.2012;142:367376. doi: 10.1378/chest.11-2279.

36. Liet JM, Dejode JM, Joram N, Gaillard-Le Roux B, Betremieux P, Roze JC. Respiratory support by neurally adjusted ventilatory assist (NAVA) in severe RSV-related bronchiolitis: a case series report. $B M C$ Pediatr. 2011;11:92. doi: 10.1186/1471-2431-11-92.

37. Venkatraman R, Hungerford JL, Hall MW, Moore-Clingenpeel M, Tobias JD. Dexmedetomidine for sedation during noninvasive ventilation in pediatric patients. Pediatr Crit Care Med. 2017;18:831-837. doi: 10.1097/PCC.0000000000001226. 
38. Essouri S, Carroll C; Pediatric Acute Lung Injury Consensus Conference Group. Noninvasive support and ventilation for pediatric acute respiratory distress syndrome: proceedings from the Pediatric Acute Lung Injury Consensus Conference. Pediatr Crit Care Med.2015;16:S102-10. doi: 10.1097/PCC.0000000000000437.

39. de la Oliva P, Schuffelmann C, Gomez-Zamora A, Villar J, Kacmarek RM. Asynchrony, neural drive, ventilatory variability and COMFORT: NAVA versus pressure support in pediatric patients. A non-randomized cross-over trial. Intensive Care Med. 2012;38:838-46. doi: 10.1007/s00134-012-2535-y.

40. Ducharme-Crevier L, Beck J, Essouri S, Jouvet P, Emeriaud G. Neurally adjusted ventilatory assist (NAVA) allows patient-ventilator synchrony during pediatric noninvasive ventilation: a crossover physiological study. Crit Care. 2015;19:44. doi: 10.1186/s13054-015-0770-7.

41. Blanch L, Villagra A, Sales B, Montanya J, Lucangelo U, Lujan M, Garcia-Esquirol O, Chacon E, Estruga A, Oliva JC, et al. Asynchronies during mechanical ventilation are associated with mortality. Intensive Care Med. 2015;41:633-41. doi: 10.1007/s00134-015-3692-6.

42. Baudin F, Emeriaud G, Essouri S, Beck J, Javouhey E, Guerin C. Neurally adjusted ventilatory assist decreases work of breathing during non-invasive ventilation in infants with severe bronchiolitis. Crit Care. 2019;23:120. doi: 10.1186/s13054-019-2379-8.

43. Mazars N, Milesi C, Carbajal R, Mesnage R, Combes C, Rideau Batista Novais A, Cambonie G. Implementation of a neonatal pain management module in the computerized physician order entry system. Ann Intensive Care. 2012;2:38. doi: 10.1186/2110-5820-2-38. 